\title{
Multi-layered Ruthenium-modified Bond Coats for Thermal Barrier Coatings
}

B. Tryon ${ }^{1}$, Q. Feng ${ }^{1}$, R.G. Wellman ${ }^{2}$, K.S. Murphy ${ }^{3}$, J. Yang ${ }^{4}$, C.G. Levi ${ }^{4}$, J.R. Nicholls ${ }^{2}$, and T.M. Pollock ${ }^{1}$

${ }^{1}$ Department of Materials Science and Engineering, University of Michigan, Ann Arbor, MI, USA

${ }^{2}$ Cranfield University, Cranfield, Bedford, MK 43 OAL, UK

${ }^{3}$ Howmet Research Corporation, Whitehall, MI, USA

${ }^{4}$ Materials Department, University of California, Santa Barbara, CA, USA

Keywords: Ruthenium aluminide; Thermal barrier coatings; Bond coat; Interdiffusion

\begin{abstract}
Diffusional approaches for fabrication of multi-layered Ru-modified bond coats for thermal barrier coatings have been developed via low activity chemical vapor deposition and high activity pack aluminization. Both processes yield bond coats comprising two distinct B2 layers, based on $\mathrm{NiAl}$ and $\mathrm{RuAl}$, however, the position of these layers relative to the bond coat surface is reversed when switching processes. The structural evolution of each coating at various stages of the fabrication process has been and subsequent cyclic oxidation is presented, and the relevant interdiffusion and phase equilibria issues in are discussed. Evaluation of the oxidation behavior of these Ru-modified bond coat structures reveals that each B2 interlayer arrangement leads to the formation of $\alpha-\mathrm{Al}_{2} \mathrm{O}_{3} \mathrm{TGO}$ at $1100^{\circ} \mathrm{C}$, but the durability of the TGO is somewhat different and in need of further improvement in both cases.
\end{abstract}

To be submitted to: Metallurgical and Materials Transactions A, 09 March 2006 


\section{Introduction}

Thermal barrier coatings (TBCs) are an enabling materials technology for advanced gas turbine engines as they expand the operating temperature capability of metallic components $[1,2]$ with attendant benefits to the engine fuel efficiency and environmental impact. A typical TBC system (Figure 1) comprises multiple layers with distinct but complementary functionalities [3]. The Ni-based superalloy component (often an internally cooled turbine blade or vane) is the loadbearing member of the system. Thermal protection is provided by the "top coat," a 100-300 $\mu \mathrm{m}$ layer of 7wt.\% yttria-stabilized zirconia (7YSZ) applied either by electron-beam physical vapor deposition (EB-PVD, as in Figure 1) or atmospheric plasma spray (APS) [2]. The coating microstructure is tailored to be "strain tolerant" by promoting columnar grains with open boundaries (EB-PVD) or microcracking of splats (APS) [3]. Incorporation of porosity during deposition reduces further the inherently low thermal conductivity of the 7YSZ thermal barrier [4-6].

Since 7YSZ is an oxygen conductor and contains extensive porosity, oxidation protection must be built in by other means, namely through a thin, dense, and continuous "thermally grown" aluminum $\alpha-\mathrm{Al}_{2} \mathrm{O}_{3}$ oxide layer (TGO in Figure 1) [7]. Zirconia generally bonds well to alumina at high temperature, and thus, the TGO also provides a strong foundation for the thermal barrier [8]. Since superalloy compositions are not typically optimized for oxidation resistance, their surfaces are chemically modified to produce a sound, durable TGO [3,9]. This modified metallic layer is known as the "bond coat" (BC) and is generally based on one or more of the intermediate Ni-Al intermetallic phases, most notably $\beta$-NiAl $(\mathrm{B} 2)$ or $\gamma^{\prime}-\mathrm{Ni}_{3} \mathrm{Al}\left(\mathrm{L}_{2}\right)$, with other elements in solid solution [10-15]. The ability of the bond coat to support the TGO is sensitive to initial processing procedures and subsequent in-service thermal cycling because its chemistry constantly changes due to oxidation and interdiffusion with the substrate [15-22]. 
Of particular interest to this study are the single phase (B2) Pt-modified NiAl-based bond coats that have been shown to outperform conventional (B2) NiAl for high temperature TBC systems $[23,24]$. These BCs are fabricated by first plating the Ni-base superalloy with a thin layer of $\mathrm{Pt}(\sim 5-7 \mu \mathrm{m}$ thick) followed by annealing at high temperature to partially diffuse the Pt into the substrate, and then aluminizing to produce the desired B2 surface layer $[12,25,26]$. The process has important implications for the substrate in that it draws $\mathrm{Ni}$ (as well as $\mathrm{Cr}$ and $\mathrm{Co}$ ) from it to form the desired intermetallic phase, promoting the formation of an interdiffusion zone (as in Figure 1) typically containing carbides and refractory metal-rich phases $[9,10]$. The characteristics of the $\mathrm{BC}$ and interdiffusion zone (IDZ) depend on the activity of the Al applied to the substrate surface during processing $[10,27,28]$. Aluminization conditions where appreciable inward diffusion of Al into the substrate takes place are referred to as "high activity" processes $[10,27,28]$. These generally form $\delta-\mathrm{Ni}_{2} \mathrm{Al}_{3}$ with small amounts of $\mathrm{NiAl}$ in the top layer of the $\mathrm{BC}$. A subsequent diffusion cycle transforms the $\delta-\mathrm{Ni}_{2} \mathrm{Al}_{3}$ into the more ductile and oxidation resistant $\mathrm{B} 2 \mathrm{NiAl}[10$, 27]. Conversely, outward Ni diffusion predominates in "low activity" processes, leading directly to the formation of $\mathrm{B} 2 \mathrm{NiAl}[10,28]$.

While the Pt-modified aluminides are attractive from an oxidation perspective, they are also prone to "rumpling" $[12,18,20,29,30]$ upon thermal cycling, wherein the TGO develops severe out-of-plane displacements that degrade the adherence of the top coat $[31,32]$. The "rumpling" mechanism is complex, motivated by one or more of the following phenomena: (i) "in-plane" growth of the TGO due to new $\alpha-\mathrm{Al}_{2} \mathrm{O}_{3}$ formation at the grain boundaries [33], (ii) "swelling" of the bond coat owing to the asymmetric interdiffusion fluxes with the substrate [20], and (iii) volume changes associated with phase transformations, which in turn are triggered by compositional changes in the $\mathrm{BC}$ as a result of oxidation and interdiffusion $[18,19]$. The stresses generated by these constrained dilatations, coupled with those produced by thermal expansion mismatch during 
thermal cycling, are accommodated by plastic deformation in the bond coat layer $[34,35]$. The associated displacements induce separations from the top coat eventually leading to spallation [12, $18,20,29,30]$.

Susceptibility to rumpling thus depends on the mechanical properties of the bond coat, and strategies for high temperature strengthening of the $\mathrm{BC}$ are desirable to suppress this failure mode $[35,36]$. Ru additions to NiAl present an opportunity for such a strategy [37]. RuAl has the same B2 structure as NiAl but its melting point is higher by $\sim 400^{\circ} \mathrm{C}[38,39]$, it has higher strength at elevated temperature [40] and exhibits characteristics suggestive of better intrinsic deformability at low temperatures compared to $\mathrm{NiAl}$ [41-43]. It has also been proposed that platinum group metals (PGMs), such as Ru, can potentially act as diffusion barriers preventing the migration of detrimental elements toward the $\mathrm{BC} / \mathrm{TGO}$ interface [44-46], with attendant benefits to the minimization of interdiffusion effects. A concern arising from recent investigations, however, is the inadequate oxidation resistance of monolithic RuAl [47]. For this reason, one would not anticipate using RuAl as a bond coat on a Ni-base superalloy without substantial alloying modifications to RuAl, so the issue becomes whether $\mathrm{Ru}$ additions can improve the mechanical performance of a NiAl-based BC without impairing its oxidation resistance. Moreover, if $\mathrm{Ru}$ were found effective as a potential replacement for $\mathrm{Pt}$, there would be economic benefits even at comparable performance.

The objectives of the present investigation are (i) to define a processing approach for fabrication of a Ru-modified aluminide bond coating and (ii) to investigate its oxidation and interdiffusion behavior in the context of the potential application into a TBC system. The interdiffusion and phase equilibria issues relevant to the fabrication of these interlayers were investigated in detail. The evolution of coating microstructures at various stages of the fabrication process was studied, and observations of the cyclic oxidation resistance of these Ru-modified aluminide bond coats are presented. 


\section{Experimental Procedures}

\subsection{Materials}

Substrates were cut from single crystal plates of CMSX $-4^{\mathrm{TM}}$ with composition, including minor element impurities, listed in Tables 1 and 2, respectively. The $\mathrm{C}$ and $\mathrm{S}$ content were measured by combustion analysis while $\mathrm{O}$ and $\mathrm{N}$ were determined by the inert gas fusion thermal conductivity method, both following ASTM Standard E1019-03 [48]. Zr and B were measured using direct current argon plasma atomic emission spectrometry in accordance with ASTM Standard E1097-03 [49]. Impurity analyses were performed by Sherry Laboratories in Muncie, IN.

The plates were sliced by electro-discharge machining (EDM) into coupons measuring approximately $3 \mathrm{~mm}$ in thickness. The EDM surfaces were glued to the base plate of a flat surface grinder. The sides of each coupon were ground to $25 \mathrm{~mm} \times 57 \mathrm{~mm}$ and the surfaces to be flat and parallel. Superalloy surfaces in contact with the casting mold as well as EDM heat-affected areas were removed during the grinding process. The surface grinder was set to remove $2.5 \mu \mathrm{m}$ of material per pass to avoid excess damage to the superalloy. The coupons were washed in acetone to remove any remaining glue and residue from the grinding process. Each coupon was then grooved part way through its thickness to form two square areas of $25 \mathrm{~mm} \times 25 \mathrm{~mm}$ on the top area of each bar and polished by hand from 240 grit to 800 grit SiC paper. Each coupon was washed multiple times in acetone to remove residues from the preparation process. The final thickness of each coupon was nominally $3 \mathrm{~mm}$.

\subsection{Coating Deposition}

Ru was deposited on the top (grooved) surfaces of the coupons using electron beam physical vapor deposition (EB-PVD). The substrate temperature varied during deposition from an initial (preheating) value of $475^{\circ} \mathrm{C}$ to approximately $500^{\circ} \mathrm{C}$. A Ru layer approximately $7 \mu \mathrm{m}$ thick was deposited on each substrate at a rate of $30-40 \mathrm{~nm} / \mathrm{s}$. The coupons were then annealed in Ar, heating 
at $8^{\circ} \mathrm{C} / \mathrm{min}$ to $1100^{\circ} \mathrm{C}$, holding for $1 \mathrm{~h}$ and then cooling at $10^{\circ} \mathrm{C} / \mathrm{min}$. Some specimens were given additional anneals at $1100^{\circ} \mathrm{C}$ for durations totaling $4 \mathrm{~h}$ and $16 \mathrm{~h}$ to characterize the kinetics of $\mathrm{Ru}$ redistribution and ascertain the most desirable treatment prior to aluminization. The selected annealing time was $4 \mathrm{~h}$.

One set of coupons was aluminized by a low activity chemical vapor deposition (CVD) process following standard practices for bond coat production [25]. Samples generated in this manner received only a $1 \mathrm{~h}$ anneal prior to aluminization because they were to spend nearly $3 \mathrm{~h}$ at elevated temperature before the actual aluminization began. The effective annealing time was thus equivalent to the desired $4 \mathrm{~h}$.

A second set of coupons was annealed for the full 4 hours at $1100^{\circ} \mathrm{C}$ and then aluminized for 25 minutes at $1050^{\circ} \mathrm{C}$ by a high temperature, high activity pack-aluminization process. These samples were individually sealed in quartz ampoules back-filled with argon and given a recovery treatment of $2 \mathrm{~h}$ at $1120^{\circ} \mathrm{C}$, followed by $24 \mathrm{~h}$ at $825^{\circ} \mathrm{C}$ as described in reference [27]. The heating rate was $100^{\circ} \mathrm{C} / \mathrm{h}$, the intermediate cooling rate was $100^{\circ} \mathrm{C} / \mathrm{h}$, and the final cooling to room temperature occurred at $50^{\circ} \mathrm{C} / \mathrm{h}$.

\subsection{Oxidation}

Preliminary cyclic oxidation studies in air were carried out on both low and high activity samples. Specimens for this study excluded the application of a thermal barrier to enable observation of the microstructural evolution and oxidation behavior of the bond coat surface in plan-view.

Coupons were sectioned into $10 \mathrm{~mm} \times 10 \mathrm{~mm}$ square samples. The sides and bottom of each sample were hand polished to 800 grit to reveal the superalloy substrate while only the topside remained in its as-aluminized state (as these smaller coupons were cut from large ones and not all sides of each specimen were exposed the aluminization treatment). After cleaning in acetone the 
samples were placed on curved alumina platens in a conventional bottom-loading cyclic oxidation furnace. The oxidation cycle was modeled after that of Meier and co-workers [50] and consisted of ramping to $1100^{\circ} \mathrm{C}$ in 10 minutes, followed by an isothermal dwell period of 45 minutes at $1100^{\circ} \mathrm{C}$ before cooling to $100^{\circ} \mathrm{C}$ in 10 minutes. Exposures included 15, 30, 60, and 120 cycles for the low activity samples and 15 and 30 cycles for the high activity specimens. The development of the oxide scale on the Ru-modified coatings and the extent of interdiffusion with the substrate were studied in detail in each of the cyclically oxidized samples.

\subsection{Characterization}

As-processed and oxidized specimens were examined in cross-section by electron microprobe analysis (EMPA) as well as by scanning electron microscopy (SEM) in secondary electron (SE) and backscattered electron (BSE) modes. A focused ion beam (FIB) instrument was used to machine out areas of interest for TEM study from the low activity as-aluminized specimen, as illustrated in Figure 2. Evidence of residual stresses within the individual coating layers was observed during TEM sample preparation, consistent with the expected changes in CTE as a result of the chemical gradients within the bond coat. Note, for example, the bending of the thin FIB sample the NiAl topcoat layer in Figure 2 as it was released from the surrounding material. Tilting experiments were carried out to generate diffraction patterns of the major constituent layers of the low activity coupons. FIB specimens were prepared at the Campus Electron Optics Facility at the Ohio State University, Columbus, $\mathrm{OH}$.

Each sample surface was analyzed using SEM and X-ray diffraction (XRD), in the asaluminized state and after various cyclic oxidation exposures. XRD was also performed on the high activity samples after the recovery heat treatment. XRD patterns were generated using $\mathrm{Cu} \mathrm{K \alpha}$ radiation in a $\Theta / 2 \Theta$ rotating anode diffractometer. Operating conditions for the diffractometer were set at $40 \mathrm{kV}$ and $100 \mathrm{nA}$ with a scan rate of $5^{\circ} / \mathrm{min}$ with $0.024^{\circ}$ steps. 


\section{Results}

\subsection{Ru-coating Interdiffusion}

Interdiffusion between the PVD Ru layer and the superalloy substrate was investigated by heat treating in Ar to identify the conditions required to produce a desirable microstructure for the subsequent aluminizing step. Preliminary experiments with a $3 \mu \mathrm{m}$ PVD Ru coating revealed preferential outward migration of $\mathrm{Ni}$ so that after $24 \mathrm{~h}$ at $1100^{\circ} \mathrm{C}$ the Ru-rich layer was "buried" completely under a Ni-rich surface layer. This phenomenon is illustrated by the BSE image and corresponding composition profile shown in Figure 3, which arguably represents the extreme case of "low activity" (zero) aluminization. By reducing the time to $4 \mathrm{~h}$ and increasing the thickness to $\sim 7 \mu \mathrm{m}$, the $\mathrm{Ru}$ enrichment is retained at the surface, as shown in Figure 4. XRD analysis confirms that the surface retains the $\delta$ - $\mathrm{Ru}$ structure up to $16 \mathrm{~h}$, although there is a continuous increase in the lattice parameters reflecting the progressive intake of elements from the substrate. Conversely, the total thickness of the Ru-enriched region is $10-12 \mu \mathrm{m}$. Closer examination of the microstructure and compositional profile in Figure 4 suggests that a new phase, enriched in Al and refractory elements (particularly Ta), has formed at the interface between the $\delta$-Ru and the superalloy. This Al-rich layer appears to prevent Ta from migrating to the surface.

\subsection{As-aluminized Microstructures}

Microstructures and composition profiles of the as-aluminized coatings using the low activity and high activity processes are shown in Figure 5. In both cases the structure consists of two dominant layers with the B2 structure, one based on NiAl and the other on RuAl. However, the low activity (LA) coating has the NiAl layer at the surface and the RuAl layer underneath (Figure 5a), whereas the order is reversed in the high activity (HA) process (Figure 5b). Moreover, XRD of the as-aluminized surfaces shows the presence of only single phase B2 in the LA coating, but a variety of intermediate/intermetallic second phases in addition to RuAl for the HA coating. These 
subsequently undergo dissolution during the annealing treatment, as discussed later. Additionally, there are significant differences in the physical appearance of the surfaces, the HA samples showing a rougher surface on a finer scale than the LA coatings, as evident in the cross sections of Figure $5 \mathrm{~b}$ and the top views in Figure 6. The grain sizes of the LA surface layer range from $\sim 20 \mu \mathrm{m}$ to $>60 \mu \mathrm{m}$ (Figure 6a), whereas that of the HA surface appear to be much smaller (Figure 6b).

The EMPA composition profiles in Figure 5a reveal an abrupt and opposite change in the concentration of $\mathrm{Ni}$ and $\mathrm{Ru}$ in the transition region between the two layers for both coatings. The bulk of the NiAl layer contains no significant $\mathrm{Ru}$ in either case, but the RuAl layer does contain $\mathrm{Ni}$ in solid solution. Moreover, the $\mathrm{Al}$ content is hypostoichiometric at all points in the LA coating but substantially hyperstoichiometric in the HA RuAl layer. Other elements from the substrate diffuse into the bond coat region with $\mathrm{Ni}$, as typical of aluminizing processes. For the low activity coating the refractory elements (W, Mo, Re and especially $\mathrm{Ta}$ ) appear to accumulate in the $\mathrm{RuAl}$ region closest to the substrate and are essentially absent in the top layer. Conversely the $\mathrm{Co}$ and $\mathrm{Cr}$ appear to migrate readily through the RuAl layer into the NiAl. The RuAl appears to act effectively as a diffusion barrier to the heavier, refractory elements while allowing outward transport of $\mathrm{Ni}, \mathrm{Cr}$ and Co during aluminization. Conversely, the concentration of $\mathrm{Cr}$ and $\mathrm{Co}$ is somewhat lower and that of refractory elements higher in the HA RuAl layer compared with the counterpart NiAl surface resulting from the LA process.

Other microstructural differences are worth noting in Figure 5 beyond the two main B2 layers. First, a typical (albeit thin) interdiffusion zone (IDZ) characterized by the presence of second phases rich in refractory elements [10] is evident in the HA coating between the substrate and the NiAl layer (Figure 5b), but no such zone is present in the corresponding LA coating. Instead, the refractory elements appear to accumulate in solid solution in the lower part of the RuAl layer, as noted previously. The total thickness of the modified layer, including the IDZ, is then 
substantially greater for the HA than for the LA coating, $\sim 55 \mu \mathrm{m}$ versus $\sim 35 \mu \mathrm{m}$, respectively. Also notable is the formation of a distinct second phase layer, tentatively identified as based on the Heusler phase $\mathrm{Ru}_{2} \mathrm{AlTa}[46,51$ ], between the $\mathrm{NiAl}$ and $\mathrm{RuAl}$ layers in the HA coating (Figure 5b) but not in the LA coating. Conversely, the LA coating exhibits intermittent elongated second phases rich in $\mathrm{Co}, \mathrm{Cr}$ and $\mathrm{Re}$ within the Ru-rich layer of the as-aluminized specimen $\sim 26-28 \mu \mathrm{m}$ below the surface of the coating (Figure 5a). As will be shown later by the oxidation experiments, these particles persist over time, whereas the $\mathrm{Ru}_{2} \mathrm{AlTa}$ phase in the HA coating dissolves into the surrounding B2 layers. About $20 \mu \mathrm{m}$ below the surface in the LA coating there is another plane of small, dark particles delineating the original position of the Ru surface prior to aluminization. This "marker" provides insight into the relative extent of inward and outward diffusion during aluminization. A comparable "marker" layer does not exist in the HA coating as the original Rurich surface continues to exist as the surface in the aluminized product.

TEM analysis of the as-aluminized LA coating in Figure 7 confirms the B2 structure of the NiAl and RuAl regions in Figure 2. The top NiAl layer (Figure 7a) had a lattice parameter of $0.288 \mathrm{~nm}$, consistent with XRD analysis of the surface and in the range of typically accepted values for NiAl [52]. Deviation from the nominal NiAl lattice parameter is ascribed to the presence of additional elements in solid solution, as noted before (Figure 5a). The image in Figure 7a also reveals extremely fine nano-scale second phases within the NiAl layer, likely precipitated during cooling. The SAD patterns taken from this region exhibit double diffraction from the embedded nano-particles, particularly in the [011] beam direction, but the scale was too small to conclusively ascertain their structure and composition.

The Ru-rich B2 region was found by XRD to have a lattice parameter in the range of 0.300 $0.304 \mathrm{~nm}$, again influenced by the presence of elements in solid solution. A bright field image and corresponding diffraction patterns of this interlayer confirm the B2 structure of this layer (Figure 
7b). This region also contained some nano-sized spheroidal particles, larger than those observed in the NiAl topcoat but still too fine to resolve by conventional TEM analysis methods. As in the NiAl layer, the SAD patterns contain extra spots, particularly in the [011] zone axis, consistent with double diffraction from the second phase particles.

\subsection{Evolution of the Low Activity Coating}

The changes in the microstructure and composition profiles for the LA coating with increasing number of cyclic oxidation exposures are given in Figure 8. It is first noted that at no point is there an IDZ similar to that formed in a comparably processed Pt-modified aluminide BC. However, a thin layer of $\gamma^{\prime}-\mathrm{Ni}_{3} \mathrm{Al}$ appears between the substrate and the RuAl B2 layer after 15 cycles (barely visible in Figure $8 \mathrm{a}$ ) and continues to grow over time to $\sim 5 \mu \mathrm{m}$ after 120 cycles (Figure 8d).

The NiAl and RuAl B2 layers remain very distinct with abrupt reciprocal changes in the concentration profiles of $\mathrm{Ru}$ and $\mathrm{Ni}$ across the interface between them. The NiAl layer grows from a thickness of approximately $14 \mu \mathrm{m}$ in the as-aluminized condition (Figure $5 \mathrm{a}$ ) to $20-22 \mu \mathrm{m}$ in thickness after 15 cycles of oxidation (Figure 8a) and then remains approximately between 20$22 \mu \mathrm{m}$ through 120 cycles (Figure 8e). Conversely, the RuAl interlayer shrinks with increasing oxidation time, from $20-22 \mu \mathrm{m}$ in the as-aluminized state to only $12-15 \mu \mathrm{m}$ after 120 cycles.

After 15 cycles of oxidation at $1100^{\circ} \mathrm{C}$, a continuous $\mathrm{TGO}$ has formed on the surface of the NiAl-rich layer and is $2-3 \mu \mathrm{m}$ in thickness (Figure 8a). The TGO does not appear to grow significantly after 30 cycles (Figure 8b) but becomes discontinuous after 60 cycles as a result of spallation. Examination of the corresponding surfaces is presented in Figure 9, where the scale is seen to be continuous up to 30 cycles. The grain boundaries of the underlying NiAl layer are clearly visible after 15 cycles (Figure 9a) and somewhat less after 30 cycles (Figure 9b). TGO cracking and spallation is observed after 60 cycles, with debris clearly noted on the surface (Figure 
9c). The remaining TGO appears to be slightly thicker at this point, in places approaching $5 \mu \mathrm{m}$ in thickness (Figure 8c). Spallation becomes even more pronounced after 120 cycles, with voids evident at the exposed surfaces of the bond coat (Figure 9d).

The Al concentration near the bond coat surface decreased from $\sim 42 \mathrm{at} \%$ to $\sim 33 \mathrm{at} \%$ after 15 cycles, and then remains near this level for the rest of the exposures. This Al decrease is attributed to the formation of oxide scale accompanied by some additional outward diffusion of $\mathrm{Ni}$, $\mathrm{Co}$ and Cr. The $\mathrm{Co}$ and $\mathrm{Cr}$ concentration in the NiAl layer remains essentially constant at $\sim 10 \%$ between 15 and 120 cycles. Only about 2 at $\%$ Ru has diffused to the NiAl/TGO interface after 15 cycles but the level gradually increases up to $\sim 8 \%$ after 60 cycles, with much of the NiAl layer showing an essentially constant $\mathrm{Ru}$ concentration at that point. Refractory elements, however, remain at trace levels near the NiAl/TGO interface even after 120 cycles suggesting that the RuAl interlayer retains its function as a diffusion barrier for these elements from the substrate.

The intermittent particles rich in $\mathrm{Co}, \mathrm{Cr}$, and $\mathrm{Re}$ seen in the as-aluminized condition have grown slightly after 15 oxidation cycles and form a nearly continuous layer across the coating, approximately $35 \mu \mathrm{m}$ below the TGO surface (Figure 8 b). These particles do not appear detrimental to the coating; however, some cracking within the RuAl layer appears approximately $25 \mu \mathrm{m}$ below the TGO surface. These cracks (Figure $8 \mathrm{~b}$ ) are apparently caused by preparation of the specimens (as they do not appear in all samples), and are likely driven by the accumulation of thermal stress within the RuAl interlayer. The semi-continuous layer of bright particles within the RuAl begins to break down, apparently by dissolution, after 30 cycles (Figure 8b) but still remain after 120 cycles (Figure 8d).

XRD analysis of the coating surface was performed at each stage of the processing and oxidation to aid in identification of phases present as the coating structure evolves at elevated temperature. The structure of the metallic phase at the surface remains single phase B2 throughout 
the 120 oxidation cycles, with additional reflections consistent with the presence of $\alpha-\mathrm{Al}_{2} \mathrm{O}_{3}$. Table 3 gives the lattice parameter $(\AA)$ of the Ru-modified NiAl LA bond coating at the various stages of oxidation exposure in comparison to the accepted lattice parameter values of the B2 compounds $\mathrm{NiAl}$ and RuAl. Note that in spite of the evident incorporation of $\mathrm{Ru}, \mathrm{Cr}$, and $\mathrm{Co}$ and the loss of $\mathrm{Al}$ the lattice parameter of the $\mathrm{B} 2$ phase deviates only slightly from that of the stoichiometric NiAl.

\subsection{Evolution of the High Activity Coating}

The evolution of the microstructure and composition profiles in the HA coating is depicted in Figure 10. The first stage prior to oxidation is the recovery annealing treatment (Figure 10a) and the most evident changes are the dissolution of the band of $\mathrm{Ru}_{2} \mathrm{AlTa}$ precipitates evident after aluminization (Figure $5 b$ ), and the significant growth of the refractory metal-rich IDZ from $\sim 5$ to $\sim 25 \mu \mathrm{m}$. The thickness of the topmost RuAl layer does not appear to change much during this treatment, remaining on the order of $25 \mu \mathrm{m}$, but the NiAl region including the matrix of the IDZ reaches nearly $50 \mu \mathrm{m}(25 \mu \mathrm{m}$ being predominately $\mathrm{NiAl}$ and $25 \mu \mathrm{m}$ being the refractory-rich IDZ) for a total coating thickness of approximately $75 \mu \mathrm{m}$ following the recovery heat treatment (Figure 10a). A thin TGO has formed even though the treatment was performed in Ar.

The EMPA profiles also show that the $\mathrm{Ru}$ and $\mathrm{Ni}$ concentrations across the RuAl/NiAl layers in the HA coating change less abruptly upon thermal exposure compared to the LA coating (Figure 10). Accordingly, the boundary between the two B2 layers becomes more diffuse over time. Most of the Ru, however, still remains concentrated on the top RuAl-based layer, although $\mathrm{Ru}$ can be found nearly $80 \mu \mathrm{m}$ away from the surface after 30 cycles of oxidation (Figure 10c). Additionally, Ni concentrations within the top layer range from $20-40$ at $\%$ at the same point, compared with only 10-20at\% after aluminization (Figure 5b). Refractory-rich as well as Co and Cr-rich phases have formed over a large area in the IDZ as shown by the particles having bright contrast in the BSE image and the EMPA profile; however, these particles do not appear to extend 
into the Ru-rich layer. The coating thickness after 30 cycles of oxidation is in excess of $100 \mu \mathrm{m}$ including the IDZ.

Examination of the coating surfaces after oxidation (Figure 11) shows that the structure retains the rough, granular appearance resulting from aluminization. The scale of the granular features on the surface is quite small, on the order of about $5 \mu \mathrm{m}$, compared with the NiAl grains in the LA coating. XRD confirms that the structure of the top layer remains B2 after the annealing treatment and throughout the multiple oxidation cycles, with only reflections for $\mathrm{RuAl}$ and $\alpha-\mathrm{Al}_{2} \mathrm{O}_{3}$ detected in the XRD pattern. The TGO thickness after both 15 and 30 cycles is approximately 2$3 \mu \mathrm{m}$; however, it is difficult to accurately ascertain the thickness of the TGO layer due to the rough surface formed by the high activity aluminization process. A more detailed analysis of the oxidation characteristics of this HA Ru-modified bond coat will be reported elsewhere.

\section{Discussion}

Two distinct processing paths have been identified for synthesizing Ru-modified bond coats. Investigations of the resultant microstructures from these two paths reveal that it is possible to selectively place a B2 Ru-modified aluminide layer either above or below a B2 NiAl layer within the $\mathrm{BC}$ by varying the activity of $\mathrm{Al}$ during the fabrication process. Characterization of the oxidized $\mathrm{BC}$ microstructures reveals that the $\mathrm{B} 2$ bi-layers remain stable throughout extended cyclic oxidation exposures at $1100^{\circ} \mathrm{C}$. Both variants of the Ru-modified $\mathrm{BC}$ structures form an $\alpha-\mathrm{Al}_{2} \mathrm{O}_{3} \mathrm{TGO}$ during oxidation whose durability is arguably insufficient for TBC applications but could, in principle, be improved with further modification to the BC system. Thermodynamic and kinetic issues relevant to the fabrication and oxidation performance of these coatings are considered in more detail in the following sections. 


\subsection{Microstructural evolution of Ru-modified bond coatings}

A unique feature of the Ru-modified bond coatings is the presence of two distinct B2 layers (Figure 5). The bi-layer BC microstructure following aluminization suggests that a miscibility gap exists between these $\mathrm{B} 2$ phases in both the LA and HA coatings. This observations is at variance with a recent experimental assessment of the Ru-Al-Ni phase diagram at $1100^{\circ} \mathrm{C}$ (Figure 12), which shows a continuous solid solution between NiAl and RuAl [53]. However, abrupt shifts in Ni and $\mathrm{Ru}$ content at the interface between the two BC layers following aluminization, and the continued stability of the adjacent NiAl and RuAl layers in both LA and HA coatings after numerous $1100^{\circ} \mathrm{C}$ oxidation cycles are clearly indicative of the presence of two distinct B2 phases. The inference is that the miscibility gap is absent in the Ru-Al-Ni ternary, but appears upon incorporation of quaternary and higher order additions present into the $\mathrm{BC}$ layer as a result of interdiffusion between the aluminized surface layer(s) and the superalloy substrate.

The emergence of a miscibility gap within the B2 field is likely to play a significant role in the microstructural differences resulting from the two distinct aluminization paths (Figure 13). In the LA case (Figure 13a), the occurrence of B2-NiAl overlying B2-RuAl in spite of Ru being originally the outermost layer is a clear manifestation of the outward flux of $\mathrm{Ni}$ (as well as Co and $\mathrm{Cr}$ ) from the superalloy which occurs during aluminization. While outward diffusion of $\mathrm{Ni}$ is the common behavior in LA processes, the resultant microstructure in these Ru-bearing BCs is distinctly different from the more conventional and similarly processed Pt-modified aluminide coatings [25]. The depletion of $\mathrm{Ni}$ from the outer substrate layer causes the precipitation of $\mathrm{Co}, \mathrm{Cr}$, and refractory-rich phases which make up the IDZ in conventional BCs [10]. In contrast, the incorporation of a RuAl interlayer between the superalloy and the NiAl appears to hinder the evolution of the IDZ. Notably, Ru from the RuAl interlayer is found to diffuse outward into the NiAl interlayer faster than inwardly into the superalloy substrate (Figure 8). Since Ru is thought to 
substitute for $\mathrm{Ni}$ in the $\mathrm{B} 2 \mathrm{NiAl}$ lattice [52], the flux of $\mathrm{Ni}$ atoms from the substrate to the coating surface, which ordinarily leads to the formation of a conventional IDZ, appears to be partially inhibited by $\mathrm{Ru}$ atoms occupying Ni sites in the NiAl layer of the $\mathrm{BC}$ as interdiffusion occurs. The formation of a Ta-rich intermetallic based on $\mathrm{RuAl}$ near the substrate-bond coat interface observed in this system has a low solubility for $\mathrm{Ni}$ which is in agreement with previous investigations [46]. This low solubility of $\mathrm{Ni}$ in Ta-containing $\mathrm{RuAl}$ restricts interdiffusion between the $\mathrm{BC}$ and the substrate and limits the precipitation of refractory-rich IDZ phases, thus acting as a buffer layer. Overall, the Ru-modification to the LA coating system appears to modify the interdiffusion between the coating and substrate, thus, preventing the formation of a conventional IDZ and perhaps slowing the development of stresses in the bond coat due to swelling.

In the HA coating (Figure 13b), the B2 layers are reversed with RuAl now being the outermost $\mathrm{BC}$ layer and NiAl located adjacent to the superalloy. This arrangement of layers results from the large inward flux of $\mathrm{Al}$ from the coating surface during high-activity aluminization. A thin IDZ at the $\mathrm{BC} /$ superalloy interface resembling that observed in convetional diffusion aluminide coatings is noted immediately after aluminization. The Ru-rich top layer of the HA processed coating becomes enriched with increasing amounts of Ni during thermal exposure (Figure 10) compared to the as-aluminized state (Figure 5b). The solubility of $\mathrm{Ni}$ in $\mathrm{RuAl}$ (or Ru in NiAl) in the environment of the multicomponent superalloy is an important issue that requires more in-depth studies for optimization of multi-layered systems.

The difference in coating thickness for the two processes is another interesting feature of these Ru-containing bond coatings. After aluminization, the thickness of the LA bond coat $(\sim 36 \mu \mathrm{m}$, Figure 5a) is thinner than either the HA bond coat ( $\sim 55 \mu \mathrm{m}$ thick, Figure $5 \mathrm{~b})$ or a similarly processed LA Pt-aluminide BC ( $\sim 60 \mu \mathrm{m}$, Figure 1$)$. The LA Ru-modified bond coating was observed to maintain a nominally consistent thickness since a conventional IDZ did not form during 
aluminization or subsequent cyclic oxidation exposure. The potential for consuming less base alloy from a blade or vane during repair prolongs its useful life; thus, the relatively slow interdiffusion kinetics in the Ru-containing coatings could result in a further benefit to the airfoil system.

The slow evolution of these two coating structures suggests slow interdiffusion following aluminization. This represents a benefit of Ru-modification to TBC system life. These BCs display diffusion barrier characteristics similar to those observed in Rh-modified coatings which prevent the outward diffusion on Ta and W that can degrade the YSZ top coat [45]. Similarly, the Ru-rich interlayer inhibits refractory elements from the superalloy substrate, particularly $\mathrm{Ta}$, from diffusing to the $\mathrm{BC}$ surface.

\subsection{Oxidation resistance of $R u$-modified coatings systems}

Previous studies on the oxidation behavior of RuAl alloys [54, 55] suggest that a RuAl-rich bond coat may not survive long in an oxidizing environment. Nevertheless, the oxidation mechanism for the Ru-containing interlayers within the BCs fabricated here is substantially different from the oxidation mechanism reported for bulk RuAl. Notably, the diffusion path operating during the fabrication of these coatings does not produce the $\delta$-Ru phase, which is known to be at the root of the poor oxidation resistance of RuAl alloys $[54,56]$. Furthermore, the $\delta$ phase is not observed during the course of oxidation of either LA or HA bond coats. During cyclic oxidation Ni diffuses into the RuAl-rich top layer making the oxidation of RuAl with varying amounts of Ni of interest for future studies. Further investigations and analysis of the HA coating oxidation will be discussed elsewhere.

The cyclic oxidation studies of the LA coating reveal that the Ni-rich surface produces a typical $\alpha-\mathrm{Al}_{2} \mathrm{O}_{3}$ TGO and offers limited protection for the RuAl-rich underlayer. However, failure of the LA Ru-modified coating occurred in relatively short times compared to Pt-modified aluminides at similar temperatures [24]. The TGO formed on the LA Ru-containing NiAl BC 
surface is only $2-5 \mu \mathrm{m}$ thick when alumina spallation was observed, while the thickness of the TGO in Pt-modified aluminide BC systems can grow to thicknesses upwards of $10 \mu \mathrm{m}$ before the onset of failure under the same cyclic oxidation conditions $[3,12]$. It is apparent that the Ru-containing NiAl interlayer oxidizes faster than conventional Pt-modified NiAl and does not exhibit the same TGO adherence as observed in Pt-aluminide systems. While spallation of the TGO occurred after only 60 cycles, no significant $\mathrm{BC}$ deformation (i.e., rumpling of the TGO) was observed in these Ru-modified coatings. It is likely, however, that the absence of rumpling may be due predominantly to the short number of cycles, suggesting that longer oxidation lives may be needed before one can ascertain conclusively the effects of $\mathrm{Ru}$ addition on hindering deformation of the bond coat during thermal cycling.

To capitalize on the potential creep strength offered by a RuAl or Ru-modified NiAl interlayer [37], further tailoring of the system response to high temperature oxidation is needed. Modification of aluminide bond coats by Pt, Ir, or Rh additions is known to improve the oxidation resistance [45, 57], and Pt-additions to bulk RuAl have also been shown to decrease its oxidation rate [56]. It is then of interest to consider the possible coating scenarios where Pt-modification could be utilized in conjunction with RuAl-containing interlayers in order to create a $\mathrm{BC}$ layer that is both creep and oxidation resistant with the ability to prevent the diffusion of refractory elements from the superalloy substrate to the $\mathrm{BC} / \mathrm{TGO}$ interface. These ideas will be explored in a forthcoming publication.

\section{Conclusions}

$>$ Two processing paths for fabrication of multi-layered Ru-modified B2 bond coats have been identified. 
The chemical composition and arrangement of these bond coat multi-layers has been shown to be process dependent: low activity CVD processing results in a NiAl outer layer, while high activity pack-aluminization produces a RuAl outer layer.

The distinct B2 layers arise from a miscibility gap that appears to be stabilized by quaternary and higher order elemental additions diffusing into the bond coat from the superalloy substrate.

$>$ In the low activity bond coating, the Ru-modified layer serves as a diffusion barrier that regulates the flux of elements contained in the substrate through the bond coat.

$>$ The Ru-modified low activity bond coating does not exhibit an interdiffusion zone characteristic of similarly produced Pt-modified aluminide bond coatings, and overall, is thinner by comparison.

The outer layers of the each bond coating form $\alpha-\mathrm{Al}_{2} \mathrm{O}_{3}$ upon exposure to high temperatures offering initial oxidation protection for the interlayers and the superalloy substrate.

\section{Acknowledgements}

This research was supported by a program of international collaboration between the National Science Foundation (DMR-0099695) and the European Commission (GRD2-200-30211). The authors wish to acknowledge useful discussions with M.F.X. Gigliotti (General Electric Global Research Center), K.J. Hemker (Johns Hopkins University), G.H. Meier (University of Pittsburgh), and D. Rickerby (Rolls-Royce), as well as the technical assistance of H. Colijn (Ohio State University), C. Henderson (University of Michigan), and C.J. Torbet (University of Michigan). CMSX $-4^{\mathrm{TM}}$ superalloy plates were supplied by J. Goedjen (SWPC, Orlando, FL). 


\section{Figure Captions}

Figure 1: A conventional TBC system structure containing a B2 Pt-modified NiAl bond coating

Figure 2: Cross-sectional SE image of FIB samples taken from the as-aluminized low activity bond coating for TEM study (courtesy of $\mathrm{H}$. Colijn, OSU)

Figure 3: $24 \mathrm{~h}$ annealing of $3 \mu \mathrm{m} \mathrm{Ru}$ coating at $1100^{\circ} \mathrm{C}$ demonstrating the preferential outward diffusion of Ni from the substrate effectively "burying" the Ru-rich layer in a low (approximately zero) Al activity system

Figure 4: BSE image and EMPA profile of Ru deposition on CMSX-4 after $4 \mathrm{~h}$ at $1100^{\circ} \mathrm{C}$

Figure 5: Cross-sectional BSE image and EMPA profiles of the as-aluminized a) CVD low activity aluminide coating; b) pack high activity aluminide coating

Figure 6: Plan-view SE images of the as-aluminized a) CVD low activity aluminide coating; b) pack high activity aluminide coating

Figure 7: TEM bright field image and corresponding diffraction patterns of the as-aluminized low activity coating: a) from the Ni-rich region; b) from the Ru-rich region

Figure 8: Low activity Ru-modified coating a) after 15 cycles of oxidation; b) after 30 cycles;

c) after 60 cycles; d) after 120 cycles

Figure 9: Plan-view SE images of CVD low activity aluminide coating surfaces a) after 15 cycles of oxidation; b) after 30 cycles; c) after 60 cycles; d) after 120 cycles

Figure 10: Cross-sectional BSE image and EMPA profiles of the high activity aluminide coating a) recovery heat treatment (RHT); b) after 15 cycles of oxidation; c) after 30 cycles

Figure 11: Plan-view SE images of high activity aluminide coating surfaces a) after 15 cycles of oxidation; b) after 30 cycles

Figure 12: Al-Ni-Ru ternary phase diagram at $1100^{\circ} \mathrm{C}(\mathrm{at} \%)[53]$

Figure 13: Formation of Ru-modified diffusion bond coating systems by two different interdiffusion processes a) low activity CVD aluminization; b) high activity pack aluminization 


\section{References}

1. S.M. Meier and D.K. Gupta: Trans ASME, 1994, vol. 116, pp. 250-7.

2. R.L. Jones: Metallurgical and Ceramic Protective Coatings, K.H. Stern ed., Chapman \& Hall, London, 1996, pp. 194-235.

3. C.G. Levi: Curr. Opin. Solid State Mater. Sci., 2004, vol. 8, pp. 77-91.

4. J.-F. Bisson, D. Fournier, M. Poulian, O. Lavigne, and R. Mévrel: J. Am. Ceram. Soc., 2000, vol. 83, pp. 1993-8.

5. T.J. Lu, C.G. Levi, H.N.G. Wadley, and A.G. Evans: J. Am. Ceram. Soc., 2001, vol. 84, pp. 2937-46.

6. M. Poulian, J.-M. Dorvaux, O. Lavigne, and R. Mévrel: Surface Modification Technologies IV, T.S. Sudarshan and M. Jeandin eds., ASM International, Materials Park, OH, 2001, pp. 495-502.

7. P.K. Wright and A.G. Evans: Curr. Opin. Solid State Mater. Sci., 1999, vol. 4, pp. 255-65.

8. R.M. Leckie, S. Krämer, M. Rühle, and C.G. Levi: Acta Mater., 2005, vol. 53, pp. 3281-92.

9. J.R. Nicholls: J. Met., 2000, vol., pp. 28-35.

10. G.W. Goward and D.H. Boone: Oxid. Met., 1971, vol. 3, pp. 475-95.

11. A.J. Hickl and R.W. Heckel: Metall. Trans. A, 1975, vol. 6, pp. 431-40.

12. A.G. Evans, D.R. Mumm, J.W. Hutchinson, G.H. Meier, and F.S. Pettit: Prog. Mater. Sci., 2001, vol. 46, pp. 505-53.

13. D.K. Das, V. Singh, and S.V. Joshi: Oxid. Met., 2002, vol. 57, pp. 245-66.

14. C.G. Levi, E. Sommer, S.G. Terry, A. Catanoiu, and M. Rühle: J. Am. Ceram. Soc., 2003, vol. 86, pp. 676-85.

15. M.J. Stiger, N.M. Yanar, M. Topping, F.S. Pettit, and G.H. Meier: Z. Metallkd., 1999, vol. 90, pp. 1069-78.

16. M.W. Chen, R.T. Ott, T.C. Hufnagel, P.K. Wright, and K.J. Hemker: Surf. Coat. Technol., 2003, vol. 163-164, pp. 25-30.

17. V.K. Tolpygo, D.R. Clarke, and K.S. Murphy: Metall. Mater. Trans. A, 2001, vol. 32A, pp. 1467-78.

18. V.K. Tolpygo and D.R. Clarke: Acta Mater., 2000, vol. 48, pp. 3283-93.

19. M.W. Chen, M.L. Glynn, R.T. Ott, T.C. Hufnagel, and K.J. Hemker: Acta Mater., 2003, vol. 51, pp. 4279-94.

20. V.K. Tolpygo and D.R. Clarke: Acta Mater., 2004, vol. 52, pp. 5129-41.

21. N. Birks, G.H. Meier, and F.S. Pettit: J. Met., 1994, vol. December 1994, pp. 42-6.

22. J.A. Haynes, M.J. Lance, B.A. Pint, and I.G. Wright: Surf. Coat. Technol., 2001, vol. 146-147, pp. 140-6.

23. J. Angenete and K. Stiller: Mater. Sci. Eng. A, 2001, vol. 316, pp. 182-94.

24. J. Angenete, K. Stiller, and V. Langer: Oxid. Met., 2003, vol. 60, pp. 47-82.

25. K.S. Murphy: USA Patent No. 5,856,027, 1999.

26. D.K. Das, V. Singh, and S.V. Joshi: Metall. Mater. Trans. A, 2000, vol. 31, pp. 2037-47.

27. J.R. Nicholls and D.J. Stephenson: Intermetallic Compounds, J.H. Westbrook and R.L.

Fleischer eds., Vol. 2 - Practice, John Wiley \& Sons, Ltd, New York, 1995, pp. 489-500.

28. J. Angenete and K. Stiller: Surf. Coat. Technol., 2002, vol. 150, pp. 107-18.

29. D.R. Mumm, A.G. Evans, and I.T. Spitsberg: Acta Mater., 2001, vol. 49, pp. 2329-40.

30. V.K. Tolpygo and D.R. Clarke: Acta Mater., 2004, vol. 52, pp. 5115-27.

31. N.R. Rebollo, M.Y. He, C.G. Levi, and A.G. Evans: Z. Metallkd., 2003, vol. 94, pp. 171-9.

32. J.A. Nychka, T. Xu, D.R. Clarke, and A.G. Evans: Acta Mater., 2004, vol. 52, pp. 2561-8.

33. D.R. Clarke: Acta Mater., 2003, vol. 14, pp. 1393-407.

34. A.M. Karlsson, J.W. Hutchinson, and A.G. Evans: J. Mater. Sci., 2002, vol. 50, pp. 1565-89. 
35. D.S. Balint and J.W. Hutchinson: Acta Mater., 2003, vol. 51, pp. 3965-83.

36. A.M. Karlsson and A.G. Evans: Acta Mater., 2001, vol. 49, pp. 1793-804.

37. B. Tryon, F. Cao, K.S. Murphy, C.G. Levi, and T.M. Pollock: J. Met., 2006, vol. 58, pp. 53-9.

38. I.M. Wolff: J. Met., 1997, vol., pp. 34-9.

39. R.D. Noebe, R.R. Bowman, and M.V. Nathal: Int. Mater. Rev., 1993, vol. 38, pp. 193-232.

40. T.K. Nandy, Q. Feng, and T.M. Pollock: Intermetallics, 2003, vol. 11, pp. 1029-38.

41. D.C. Lu and T.M. Pollock: Acta Metall., 1998, vol. 47, pp. 1035-42.

42. D.C. Lu and T.M. Pollock: Mater. Res. Soc. Symp. Proc., 1999, vol. 552, pp. KK7.11.1KK7..5.

43. T.M. Pollock, D.C. Lu, X. Shi, and K. Eow: Mater. Sci. Eng. A, 2001, vol. 317, pp. 241-8.

44. I.T. Spitsberg, R. Darolia, M.R. Jackson, J. Zhao, and J.C. Schaeffer: USA Patent No. 6,306,254 B1, 2001.

45. P.K. Datta, J.S. Burnell-Gray, and K. Natesan: Intermetallic Compounds, J.H. Westbrook and R.L. Fleischer eds., Vol. 3 - Progress, John Wiley \& Sons, Ltd., New York, 2002, pp. 561-88.

46. B. Tryon, Q. Feng, and T. Pollock: Intermetallics, 2004, vol. 12, pp. 957-62.

47. P.J. Bellina, A. Catanoiu, F.M. Morales, and M. Rühle: J. Mater. Res., 2006, vol. 21, pp. 27686.

48. ASTM: Designation: E 1019, 2003.

49. ASTM: Designation: E 1097, 2003.

50. N.M. Yanar, M.J. Stiger, M. Maris-Sida, F.S. Pettit, and G.H. Meier: Key Eng. Mater., 2001, vol. 197, pp. 145-64.

51. Q. Feng, T.K. Nandy, and T. Pollock: Scripta Mater., 2004, vol. 50, pp. 849-54.

52. P. Gargano, H. Mosca, G. Bozzolo, and R.D. Noebe: Scripta Mater., 2003, vol. 48, pp. 695700.

53. B. Tryon and T.M. Pollock: Submitted to Mater. Sci. Eng. A, 2006.

54. P.J. Bellina, A. Catanoiu, F.M. Morales, and M. Rühle: The formation of discontinuous $\mathrm{Al}_{2} \mathrm{O}_{3}$ layers during high-temperature oxidation of RuAl alloys, 2005, vol. in press.

55. F. Mücklich and N. Ilic: Intermetallics, 2004, vol. 13, pp. 5-21.

56. F. Cao, T.K. Nandy, D. Stobbe, and T.M. Pollock: Intermetallics, 2006, vol.

57. G. Fisher, P.K. Datta, and J.S. Burnell-Gray: Surf. Coat. Technol., 1999, vol. 113, pp. 259-67. 
Table 1: CMSX-4 Superalloy Composition

\begin{tabular}{|c|c|c|c|c|c|c|c|c|c|c|c|}
\hline Element & $\mathrm{Al}$ & $\mathrm{Ta}$ & $\mathrm{W}$ & $\mathrm{Re}$ & $\mathrm{Mo}$ & $\mathrm{Cr}$ & $\mathrm{Co}$ & $\mathrm{Ti}$ & $\mathrm{Hf}$ & $\mathrm{Ru}$ & $\mathrm{Ni}$ \\
\hline $\mathrm{at} \%$ & 12.2 & 2.2 & 2.0 & 1.0 & 0.4 & 7.6 & 9.3 & 1.3 & 0.1 & 0.0 & Balance \\
\hline $\mathrm{wt} \%$ & 5.6 & 6.5 & 6.0 & 3.0 & 0.6 & 6.5 & 9.0 & 1.0 & 0.1 & 0.0 & Balance \\
\hline
\end{tabular}

Table 2: CMSX-4 Superalloy Impurities and Test Method

\begin{tabular}{|c|c|c|c|c|c|c|}
\hline Element & $\mathrm{B}$ & $\mathrm{C}$ & $\mathrm{O}$ & $\mathrm{N}$ & $\mathrm{S}$ & $\mathrm{Zr}$ \\
\hline Impurity (wppm) & $20-25$ & $35-50$ & $5-37$ & $10-15$ & $\sim 3$ & $50-75$ \\
\hline Testing method & DCP & $\mathrm{CO}$ & $\mathrm{IG}$ & $\mathrm{IG}$ & $\mathrm{CO}$ & DCP \\
\hline ASTM standard & E1097-03 & E1019-03 & E1019-03 & E1019-03 & E1019-03 & E1097-03 \\
\hline
\end{tabular}

Table 3: Lattice Parameters $(\AA)$ of Ru-modified Low Activity Bond Coating with High Temperature Cyclic Oxidation Exposure

\begin{tabular}{|c|c|}
\hline Cycle Number & Lattice Parameter $(\AA)$ \\
\hline 0 (as-aluminized) & 2.88 \\
\hline 15 & 2.88 \\
\hline 30 & 2.89 \\
\hline 60 & 2.90 \\
\hline 120 & 2.89 \\
\hline & \\
\hline NiAl [39] & 2.89 \\
\hline RuAl [52] & 2.95 \\
\hline
\end{tabular}




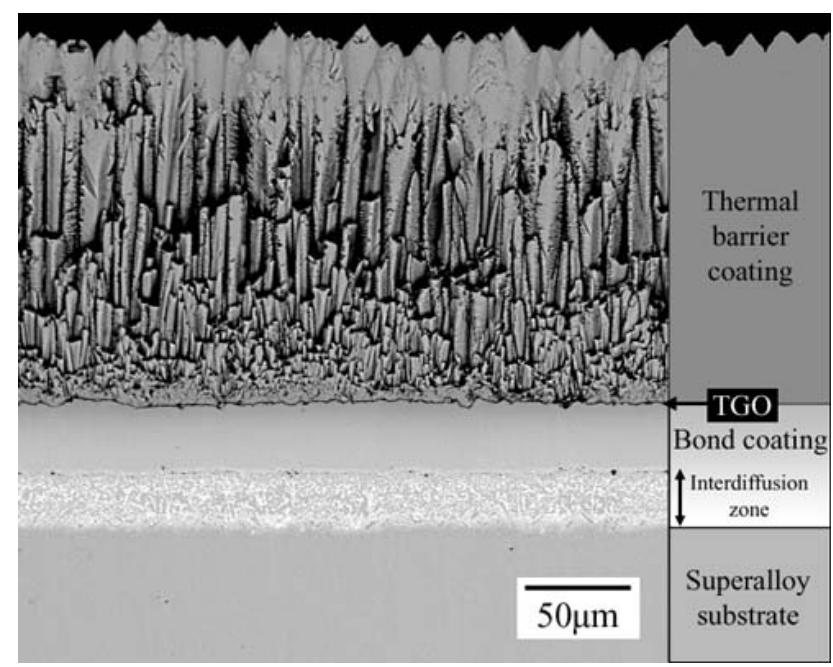

Figure 1: A conventional TBC system structure containing a B2 Pt-modified NiAl bond coating

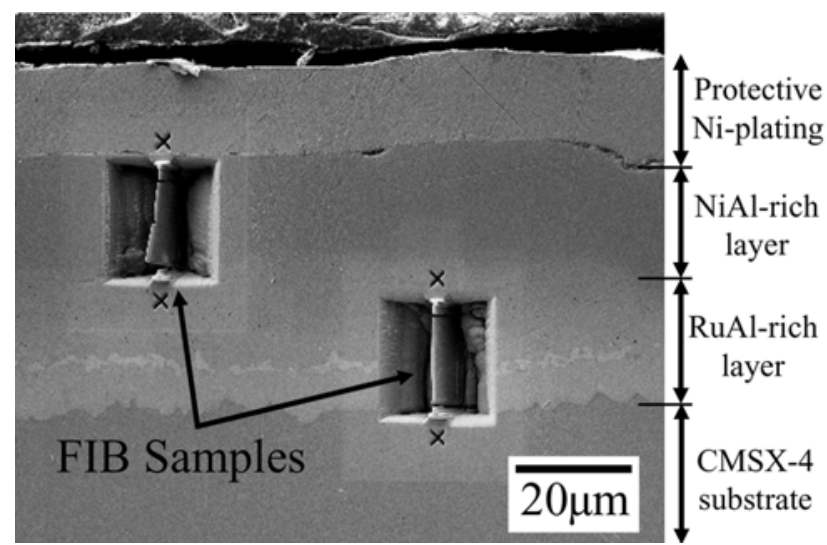

Figure 2: Cross-sectional SE image of FIB samples taken from the as aluminized low activity bond coating for TEM study (courtesy of H. Colijn, OSU)

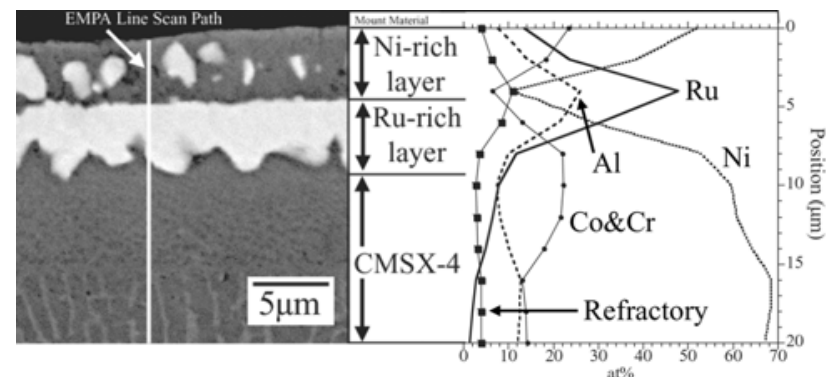

Figure 3: $24 \mathrm{~h}$ annealing of $3 \mu \mathrm{m} \mathrm{Ru}$ coating at $1100^{\circ} \mathrm{C}$ demonstrating the preferential outward diffusion of $\mathrm{Ni}$ from the substrate effectively "burying" the Ru-rich layer in a low (approximately zero) Al activity system

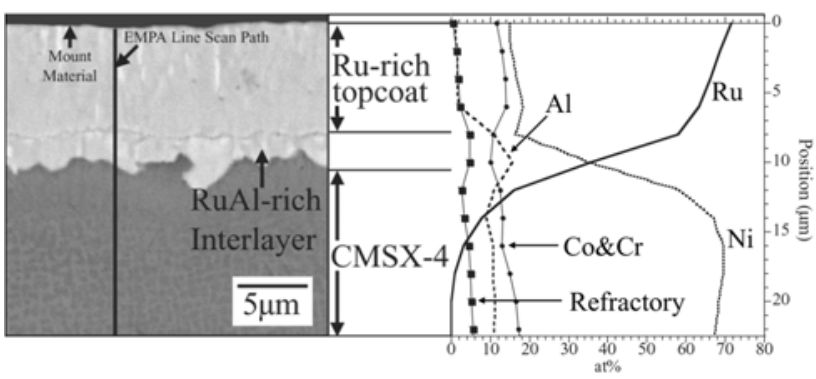

Figure 4: BSE image and EMPA profile of $\mathrm{Ru}$ deposition on CMSX-4 after $4 \mathrm{~h}$ at $1100^{\circ} \mathrm{C}$

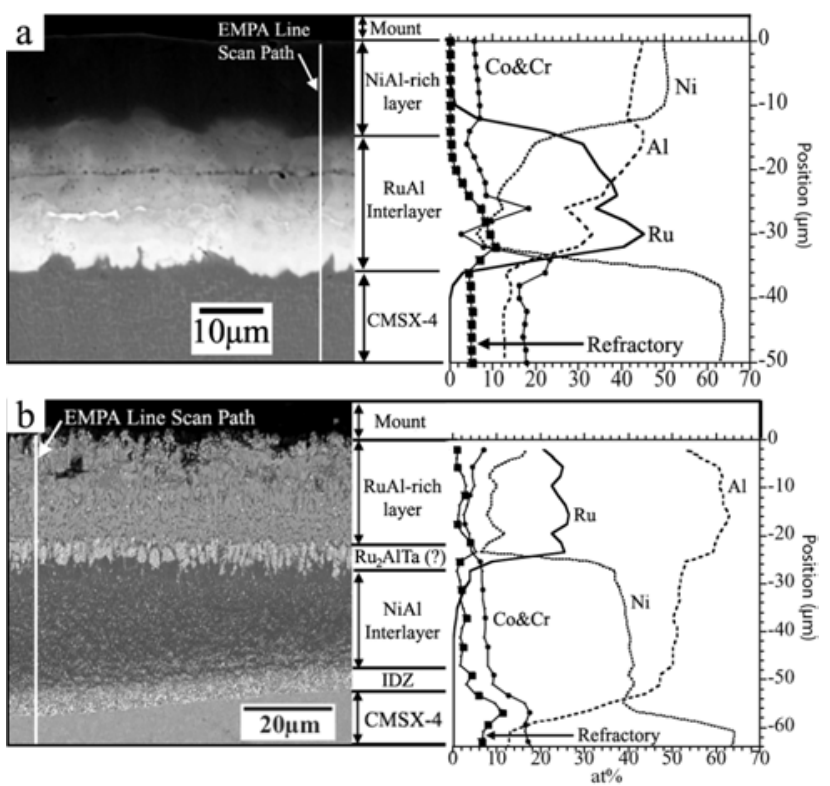

Figure 5: Cross-sectional BSE image and EMPA profiles of the as-aluminized a) CVD low activity aluminide coating; b) pack high activity aluminide coating
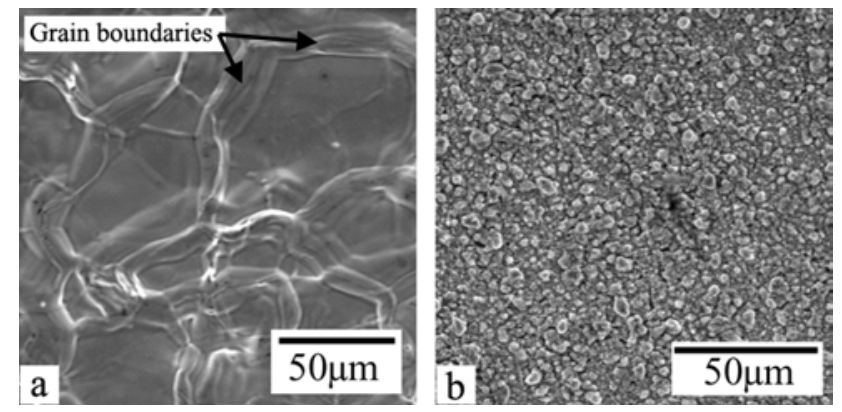

Figure 6: Plan-view SE images of the asaluminized a) CVD low activity aluminide coating; b) pack high activity aluminide coating 


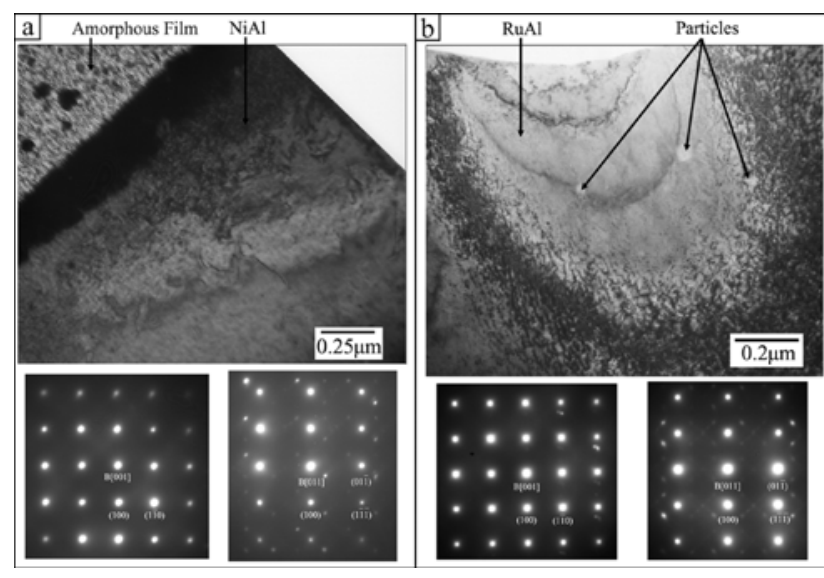

Figure 7: TEM bright field image and corresponding diffraction patterns of the asaluminized low activity coating: a) from the $\mathrm{Ni}$ rich region; b) from the $\mathrm{Ru}$-rich region
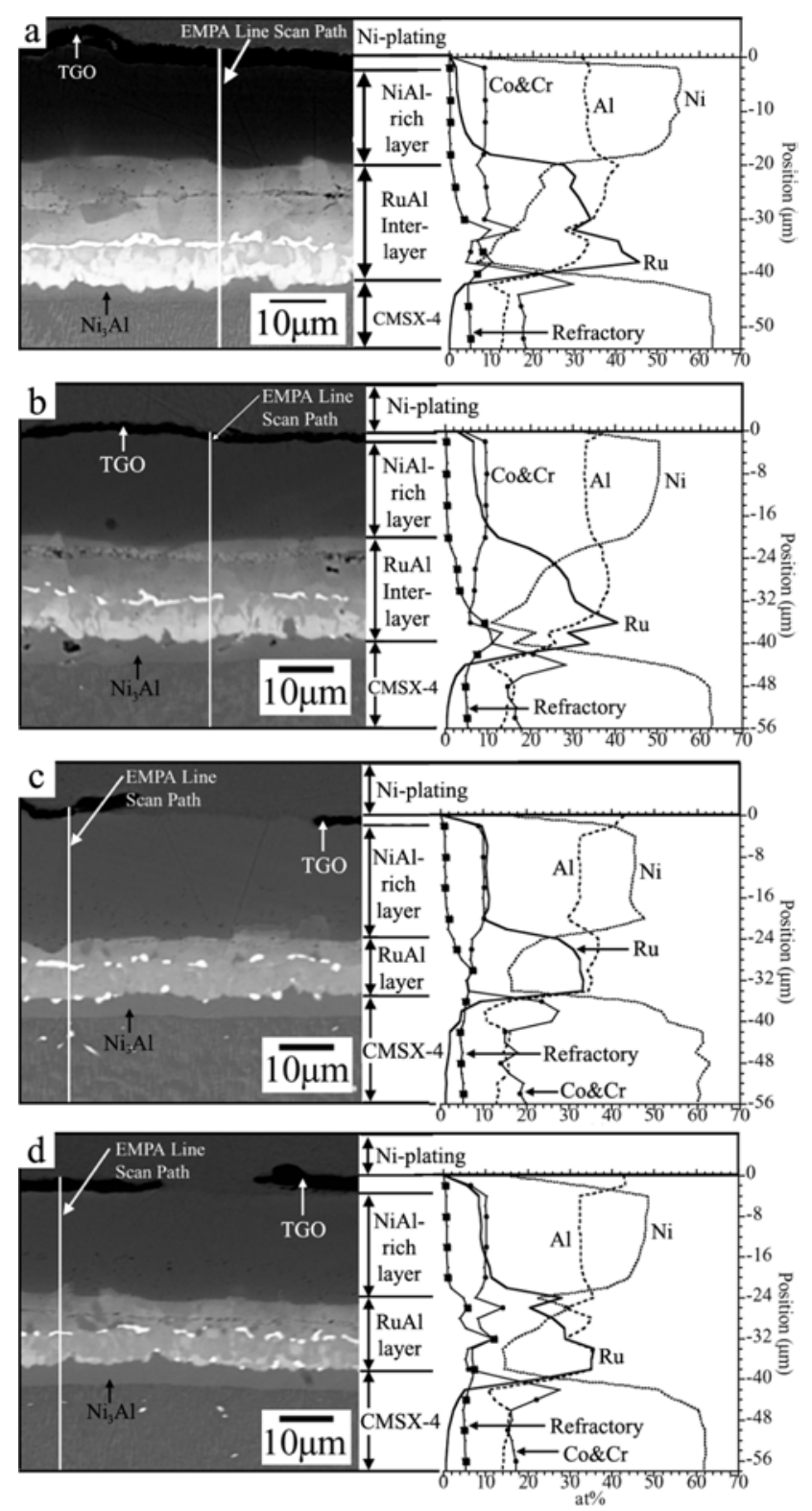

Figure 8: Low activity Ru-modified coating a) after 15 cycles of oxidation; b) after 30 cycles; c) after 60 cycles; d) after 120 cycles 

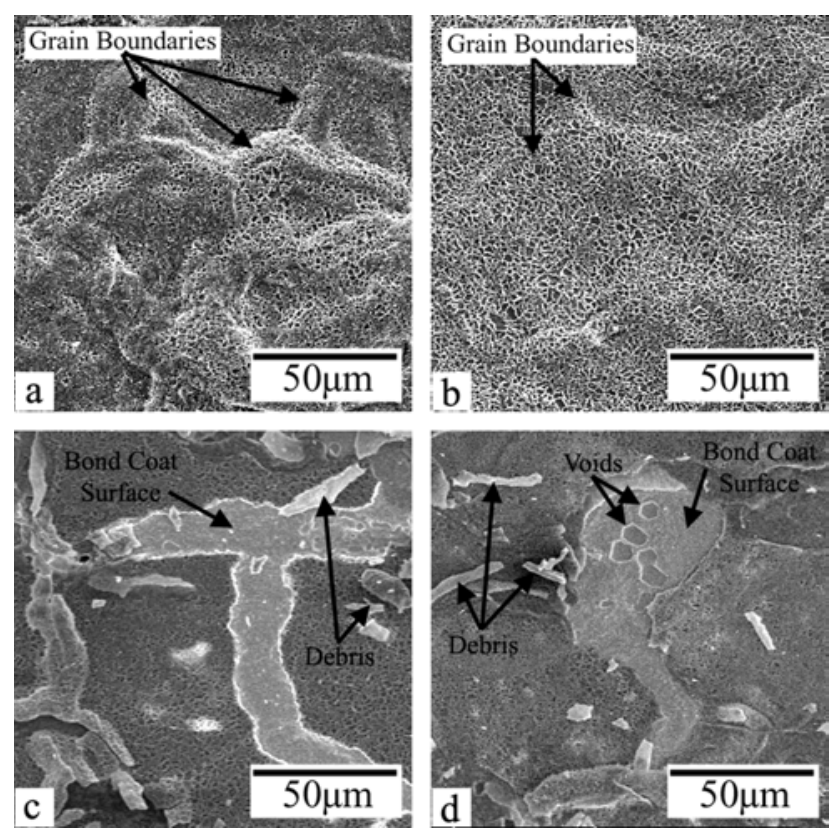

Figure 9: Plan-view SE images of CVD low activity aluminide coating surfaces a) after 15 cycles of oxidation; b) after 30 cycles; c) after 60 cycles; d) after 120 cycles
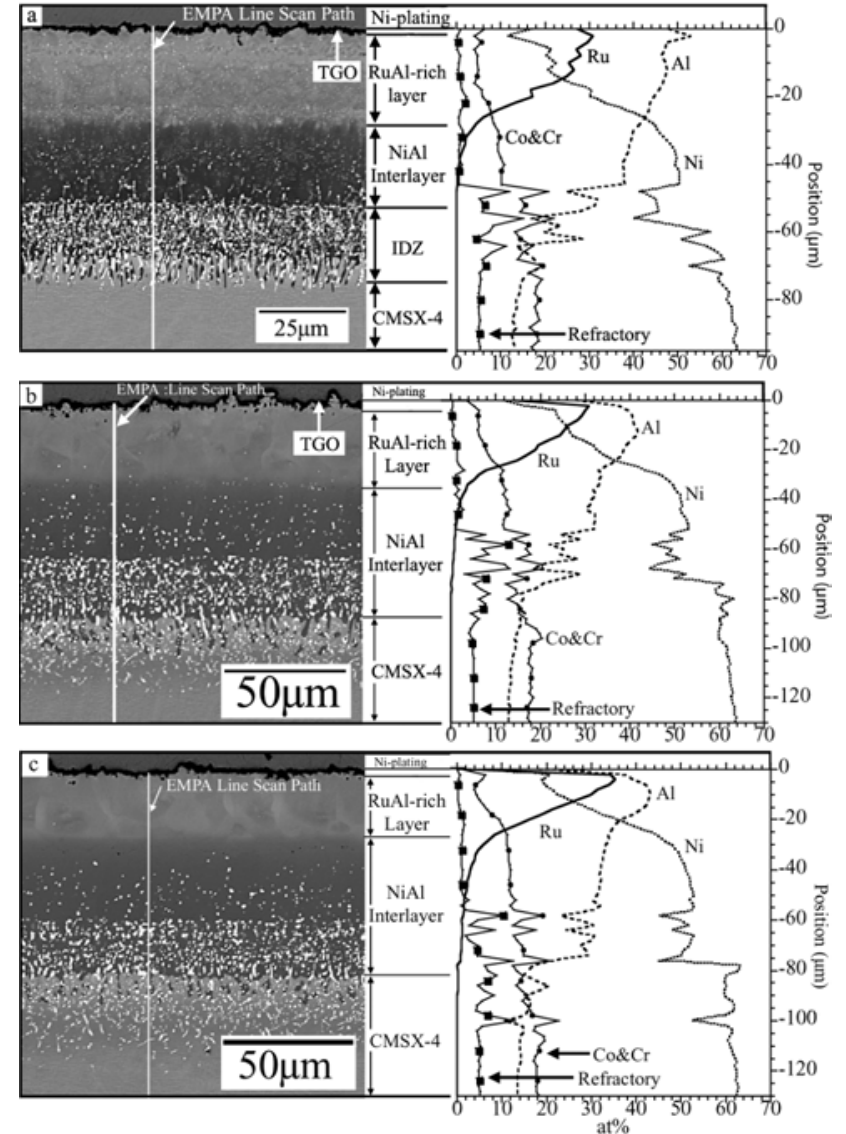

Figure 10: Cross-sectional BSE image and EMPA profiles of the high activity aluminide coating a) recovery heat treatment (RHT); b) after 15 cycles of oxidation; c) after 30 cycles
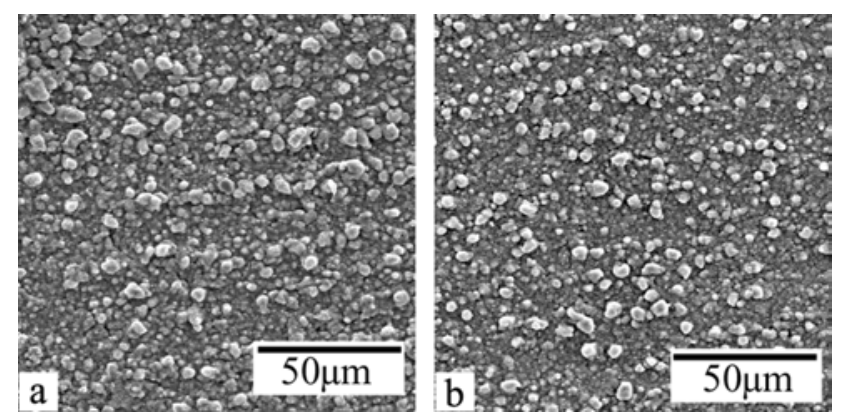

Figure 11: Plan-view SE images of high activity aluminide coating surfaces a) after 15 cycles of oxidation; b) after 30 cycles 


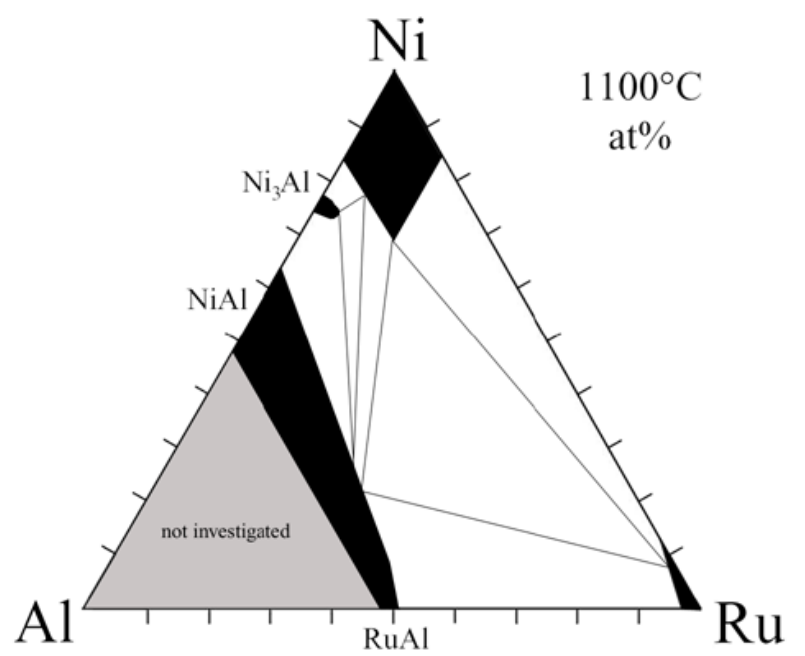

Figure 12: Al-Ni-Ru ternary phase diagram at $1100^{\circ} \mathrm{C}($ at $\%)$ [53]

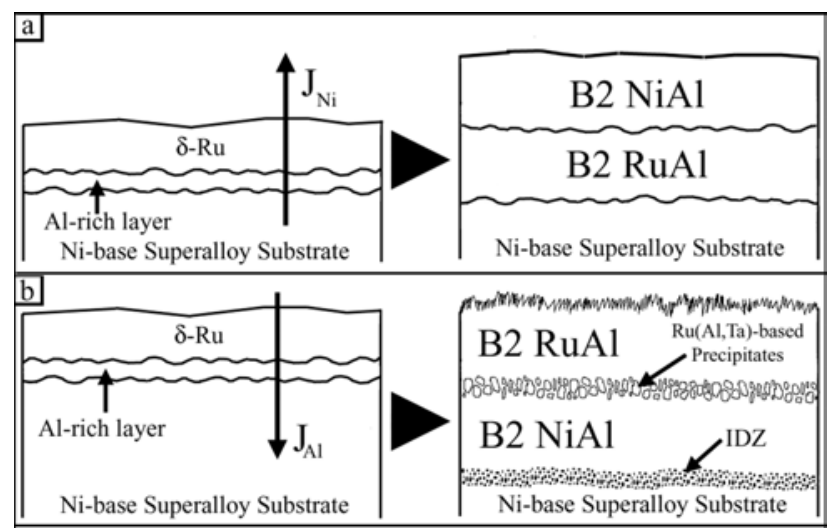

Figure 13: Formation of Ru-modified diffusion bond coating systems by two different interdiffusion processes a) low activity CVD aluminization; b) high activity pack aluminization 